\title{
Epistemological Perspectives on IS-Development - A Consensus-Oriented Approach on Conceptual Modeling
}

\author{
Björn Niehaves, Karsten Klose, Ralf Knackstedt, Jörg Becker \\ European Research Center for Information Systems (ERCIS), \\ University of Muenster, Leonardo-Campus 3, 48149 Münster, Germany \\ \{Bjoern.Niehaves, Karsten.Klose, \\ Ralf.Knackstedt, Becker\}@ercis.de \\ http://www.ercis.de
}

\begin{abstract}
Within the information systems (IS) research discipline, conceptual modeling is widely discussed as a fundamental task for IS-development as it leads to shared domain knowledge between IS developers and business personnel. As well as IS-research modeling takes place within a multi-disciplinary and multi-cultural context. Thereby, the (mostly implicit) assumptions made by different researchers may vary fundamentally. As a result, it is important to expose the epistemological assumptions which underlie the work of different participants. Thus, we discuss epistemological assumptions which are basic to IS research giving the example of the consensus-oriented approach.
\end{abstract}

Keywords: IS development, IS research, conceptual modeling, epistemological assumptions, consensus-oriented approach

\section{Lack of epistemological funding in IS research}

Information systems (IS) research today already takes places in an international and also multi-disciplinary context. But the (mostly implicit) epistemological assumptions which underlie different research approaches may vary deeply due to the disciplinary and national background of the researchers [10]. Against the background of distinct hidden (epistemological) assumptions, working on the same research topic or studying the same phenomenon of interest [15] does not necessarily mean that mutual understanding prevails. In this respect, the discussion of epistemological assumptions of IS research is almost mandatory. Nevertheless, the lack of epistemological funding of IS research methods is apparent and discussed extensively within the discipline [2], [6], [9]. Thus, the aim of this article is to discuss basic epistemological assumptions of a consensus-oriented interpretivist approach to conceptual modeling (also referred to as consensus-oriented approach). 


\section{The Consensus-Oriented Approach to Conceptual Modeling}

The consensus-oriented approach is standing in the tradition of the critical linguistic approach [3], [4], [5] which is also referenced by other related approaches to conception modeling [7], [11], [15]. Figure 1 provides an overview of its most important elements and their dependencies. The approach aims to create a linguistic community. Against the background of IS-development, this community facilitates information system designers and business personnel to overcome communicational problems. [1], [13].

At first, we assume that there is a real world existing independently from human speech and thinking processes. Thus, we assume the ontological realism. Secondly, the approach aims to create a linguistic community. Against the background of ISdevelopment, this community facilitates information system designers and business personnel to overcome communicational problems [1], [13]. Linguistic communities can be created through the (re)construction of an ortho-language. First parts of the language can be formed by the alignment of individual (real world) objects to nominators. In the context of IS-development important nominators are terms such as 'customer Meier', 'product 4711' etc. Based on nominators, predicators (in our context, for instance, 'customer' and 'product') are introduced in order to expose and communicate similarities of individual objects. A language is hence a basic instrument for each subject to gain knowledge about the real world. Language has in this case immense impact on a subject's perceptional processes. It defines the very basic perception and differentiation system. Shared language means shared conceptualizations about the real world among the members of a particular linguistic community. By designing but especially using certain language(s), the (researching) subject has great influence within the process of gaining knowledge. Thirdly, an extensive discussion on conceptual modelling in the move of information systems can be found in the literature [13]. Thus, in the move of the consensus-oriented approach, two distinct languages come into play: particular conceptual modelling languages as well as natural languages. Following Tarski [12] the creation of the linguistic community takes place on two levels. On the first level (here named $\mathrm{T}^{*}$ object language) conceptual model statements are expressed. For instance, using Entity Relationship Models (ERM) members of the linguistic community have to agree upon the term 'entity type'; in the case of Event Driven Process Chains (EPC) they have to agree upon the term 'event'. Moreover, a distinction between a) the language of model instances and b) the language of the modeling method and technique has to be made. On the second level (here named $\mathrm{T}^{*}$ meta language) members of the community have to agree on a language which facilitates them to debate about the truth and nontruth of the statements represented in a model (including for instance German or English). In the next step, the meta language $T^{*}$ is used to discuss the modeling system which is formulated on the first level using the $\mathrm{T}^{*}$ object language until a consensus of a group of experts is achieved. Afterwards, the results can be evaluated within the scope of the interpersonal verification [3], [4]. The formalized linguistic statements contained in a conceptual model are logically decomposed (deduction) until they are accessible as elemental statements for purposes of truth verification. This takes place by means of a 
group of experts who obtain a consensus. The main instruments are observation, experiments, interviewing and the interpretation of texts [3]. The validity of statements in the model can be confirmed, for example, in the case of business specific models, with a single case. In case of a pattern or reference model, however, the generalized abstraction of different individual verifications (induction) is necessary. Here, research methods such as field experiments, surveys, case studies or action research can be applied. Based on these results a revision of the conceptual model is required.

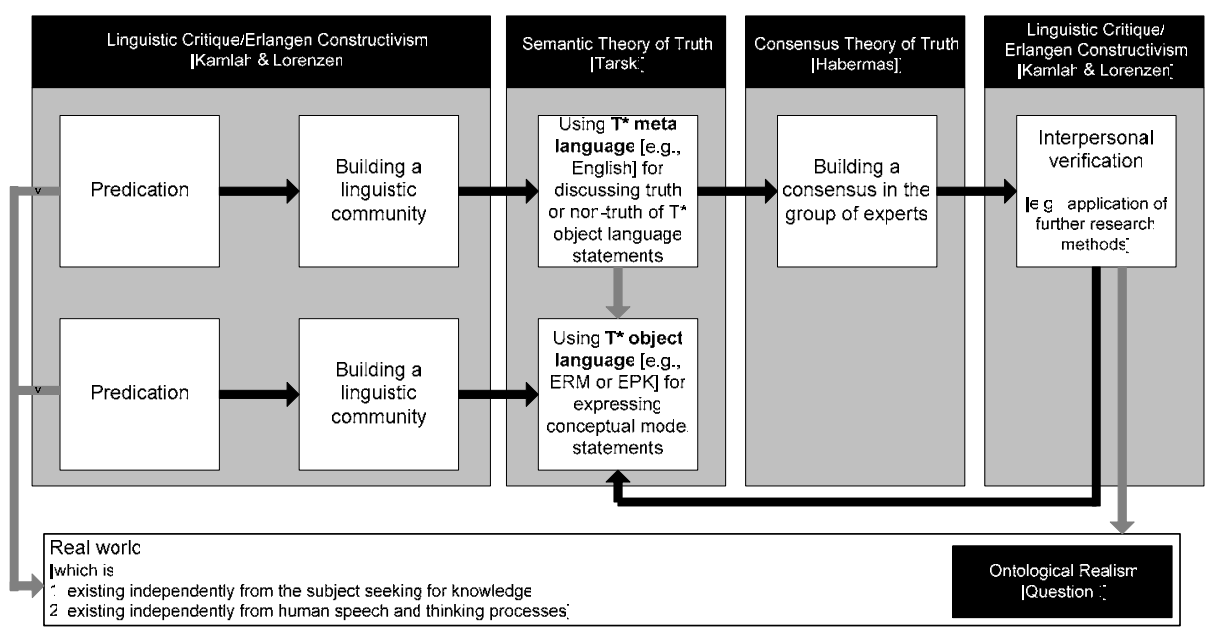

Figure 1. Elements of the consensus-oriented approach

Furthermore, the consensus-oriented approach takes the following epistemological positions: Where does cognition derive from? (Source of the cognition capability). Both empirical statements [4] and a priori statements can be made, which may form the basis of conceptual models. Conceptual modeling therefore derives its results via theoretical reflection of the model contents, as well as from the implementation of the model in information systems and through observation. How does cognition emerge? (Methodological aspect). Conceptual models are one form of artefacts of a formalized language and can contain both empirical and a priori knowledge. Inductive, deductive as well as hermeneutic conclusions can be accessed firstly in the context of the model creation and secondly in the context of truth verification.

The information models developed contain formalized linguistic statements to be tested for validity in combination with additional (empirical) research methods. This is done through members of a linguistic community in order to obtain consensus. Therefore, elements of the semantic theory of truth and the consensus theory of truth are considered and used. 


\section{Conclusions and future research}

IS research takes place in a multi-disciplinary and international context. As a consequence, the IS field can be described as a rich tapestry of different methodological approaches. Underlying assumption often vary fundamentally. Thus, we analyzed the epistemological assumptions to the consensus-oriented interpretivist approach to conceptual modeling. Interdependencies between distinct epistemological theories, namely the semantic theory of truth and the consensus theory of truth, have been discussed intensively. For future research, the discussion of interdependencies between certain epistemological questions and answers has to be carried out in greater extend. Here, a differentiation of distinct types of relations/interdependences such as 'logically necessary', 'product of the historical philosophical debate' or 'can be found in most dominant epistemological paradigms' - can be very helpful.

\section{References}

1. Becker, J.; Ribbert, M.; Dreiling, A.: Contribution of Meta Models to Systems Engineering - A CRM Example. In: Information Systems Foundation: Building the Theoretical Base. Canberra (2003) 191-204

2. Fitzgerald, G. et al.: Information Research Methodology: An Introduction to the Debate. In: Mumford, E.; Fitzgerald, G.; Hirschheim, R.; Wood-Harper, A. T. (eds.): Research Methods in Information Systems, proceedings of the IFIP (International Federation for Information Processing) WG 8.2 Colloquium, Manchester Business School, 1-3rd September 1984. Amsterdam 1985 3-9

3. Kamlah, W.; Lorenzen, P.: Logical Propaedeutic. Lanham/MD (1973)

4. Kamlah, W.; Lorenzen, P.: Logical Propaedeutic. Pre-School of Reasonable Discourse. University Press of America, Lanham, MD (1984)

5. Kamlah, W.; Lorenzen, P.: Logische Propädeutik. Vorschule des vernünftigen Redens. 3. edn. Stuttgart, Weimar (1996)

6. Keen, P. G. W.: MIS Research: Reference Disciplines and a Cumulative Tradition. In: Proceedings of the First International Conference on Information Systems. Philadelphia/PA (1980) 9-18

7. Lorenzen, P.: Constructive Philosophy. The University of Massachusetts Press, Amherst, MA, USA (1987)

8. Luft, A. L.: Rationaler Sprachgebrauch und orthosprachliche Standardisierung als Grundlagen des Software Engineering. Informatik Spektrum 4 (1982) 209-223

9. Mingers, J.: Combining IS research methods: towards a pluralist methodology. Information Systems Research (2001) 240-259

10. Orlikowski, W. J.; Baroudi, J.: Studying information technology in organizations: research approaches and assumptions. Information Systems Research (1991) 1-28

11. Ortner, E.: Methodenneutraler Fachentwurf. Stuttgart, Leipzig (1997)

12. Tarski, A. (1944) The Semantic Concept of Truth and the foundation of semantics, Philosophy and Phenomenological Research, 4/1944, 341-375.

13. Wand, Y.; Weber, R.: Research Commentary: Information Systems and Conceptual Modeling - A Research Agenda. Journal of Information Systems 2 (2002) 217-237

14. Weber, R.: Editor's Comment: Theoretically Speaking. MIS Quarterly 3 (2003) iii-xii

15. Wedekind, H.: Datenbanksysteme I, Eine konstruktive Einführung in die Datenverarbeitung in Wirtschaft und Verwaltung. 2. edn. Mannheim et al. (1981) 